\title{
Randomised controlled trials of group interventions with an individual level comparator: are appropriate statistical methods being used?
}

\author{
Lucy Bradshaw*, Alan Montgomery \\ From 3rd International Clinical Trials Methodology Conference \\ Glasgow, UK. 16-17 November 2015
}

\section{Background}

Differential clustering can occur in trials when a groupbased intervention is compared with a control arm in which participants are treated individually. Recommendations for the design and analysis of this type of trial have been published. This review aimed to investigate use of these methods in trials of group interventions with an individual level comparator.

\section{Methods}

Protocols of randomised trials published in Trials journal in 2013 and 2014 were reviewed. Data were extracted by one reviewer on randomisation, the group intervention, the sample size calculation and the planned statistical analysis.

\section{Results}

A total of 738 protocols were published in Trials in 2013/ 2014 and 37 (5\%) were included in the review. Group interventions included psychological therapies, lifestyle interventions, parenting programmes and exercise interventions. Sample sizes ranged from 35 to 796, median 112 and all used a 1:1 allocation ratio. Eight trials (22\%, 95\% CI 9\% to 38\%) recognised the potential for differential clustering between treatment arms. Three trials inflated the sample size of the trial, three trials planned to account for the differential clustering between the groups in the primary analysis and three trials planned to explore the effect of differential clustering in a planned sensitivity analysis.

\section{Conclusions}

Only a small number of protocols identified the potential for differential clustering and accounted for it in the

Nottingham Clinical Trials Unit, University of Nottingham, Nottingham, UK design or planned analysis, despite the availability of appropriate methods to do so. Results from trials that fail to recognise such clustering require careful interpretation.

Published: 16 November 2015

doi:10.1186/1745-6215-16-S2-P125

Cite this article as: Bradshaw and Montgomery: Randomised controlled trials of group interventions with an individual level comparator: are appropriate statistical methods being used? Trials 2015 16(Suppl 2):P125.
Submit your next manuscript to BioMed Central and take full advantage of:

- Convenient online submission

- Thorough peer review

- No space constraints or color figure charges

- Immediate publication on acceptance

- Inclusion in PubMed, CAS, Scopus and Google Scholar

- Research which is freely available for redistribution
() Biomed Central 